\title{
Suppression of Spontaneous Ovulation by Interruption of Dorsal Input of Hypothalamus at Various Timings during Rat Estrous Cycle
}

\author{
Miho WATANABE and Korehito YAMANOUCHI \\ Neuroendocrinology, Department of Basic Human Sciences, School of Human \\ Sciences, Waseda University, 2-579-15, Mikajima, Tokorozawa, Saitama 359-1192, \\ Japan
}

\begin{abstract}
To clarify the role of the extrahypothalamic input to the preoptic area (POA)-medial basal hypothalamus $(\mathrm{MBH})$ on spontaneous ovulation, the dorsal cut of the POA-MBH was performed on various days and ova were counted in female rats. An anterior half-circle cut (anterior dorsal cut; ADC) was performed at the dorsal of the POA on the day of proestrus. As a result, ovulation was seen on the day of estrus when ADC was performed in the evening (18:0019:30 h) but did not occur when performed in the morning (10:00-11:30 h). Furthermore, the suppressive effect of ADC was observed, even when cut was performed in the evening 2-5 days before estrus. These results suggest that the dorsal input to the POA-MBH plays an important role in ovulation-triggering mechanisms. In addition, about 7 days after the ADC, regular estrous cycle and normal ovulation were seen. Furthermore, destruction of the medial or bilateral lateral septum was done in the morning of proestrus, to investigate the role of gonadotropin-releasing hormone $(\mathrm{GnRH})$ neurons in these areas. Lesions in the septal area had no effect, suggesting that the inhibitory effect on ovulation of the ADC is not due to interruption of the fibers of the septum including GnRH neurons.
\end{abstract}

Key words: Spontaneous ovulation, Extrahypothalamic influence, Cuts, Rats.

(J. Reprod. Dev. 46: 39-45, 2000)

M ost spontaneous ovulators possess the regulatory system for cyclic ovulation in the central nervous system. In female rats, the ovulationregulating mechanism exists in the forebrain, especially in the preoptic area (POA) and the medial basal hypothalamus $(\mathrm{MBH})$, according to many reports that damage to these areas causes severe impairment of ovulation. Destruction of the $\mathrm{MBH}$ induces anovulatory syndrome with persistent vaginal diestrus [1]. On the other hand, lesions in the POA inhibit ovulation and induce

Accepted for publication: December 16, 1999

Correspondence: K. Yamanouchi persistent vaginal estrus [2, 3]. From these results, it is postulated that the POA is a cyclic releasing center and the $\mathrm{MBH}$ is a tonic secretion center for gonadotropin [4]. The surge of gonadotropinreleasing hormone $(\mathrm{GnRH})$ [5] is responsible for the gonadotropin surge followed by ovulation. The GnRH secretory neural cell bodies exist mainly in the POA and the medial septal area in rats $[6,7]$.

On the other hand, limbic areas such as the amygdala [8-10] and the hippocampus $[9,11]$ exert critical influences in regulating ovulation. In the lower brainstem, the raphe nuclei [12-14] and the locus coeruleus [13] are also involved in regulatory mechanisms for ovulation. These extrahypothalamic areas send axons to the POA-MBH and 
are thought to affect ovulation.

The dorsal afferents of the POA have been reported to play an important role during proestrous events for ovulation, because cuts of the fibers at the dorsal of the POA in the morning of proestrus suppress luteinizing hormone (LH) surge and ovulation in female rats [15-17].

In this experiment, to confirm these results and to investigate the intensity of ovulation-suppressive effects by the dorsal cuts of the hypothalamus, the cut was made on various days and ovulation was checked on the following two days in female rats. In addition, the medial septum or the bilateral lateral septum which are located at the dorsal of the POA was lesioned and occurence of ovulation was also investigated.

\section{Materials and Methods}

\section{Animals}

Female Wistar rats were housed under controlled photoperiod (14L:10D, lights on from 07:00 to 21:00 h) and temperature (23-25 C). Food and water were available ad libitum. Vaginal smears were taken through the experiments and only rats exhibiting 2 or more consecutive regular 4 -day estrous cycles were used.

\section{Measurement of number of ova in estrus and diestrus I in rat}

In the preliminary experiment, to evaluate the method for counting ova in unilateral oviduct in a rat, the left oviduct was dissected under ether anesthesia in the estrous morning and ova were counted under a microscope in 8 females. On the morning of the next day (diestrus I), animals were killed by overexposure to ether and ova in the remained right side oviduct was checked. Ten and 7 females were autopsyed on the morning of estrus and diestrus I, respectively, and ova in left and right side oviducts were counted at the same time. As a result, this method for counting ova in unilateral oviduct is useful for evaluating ovulation during consecutive 2 days (see Results).

Effects of transections of the dorsal inputs to the POA-MBH at various timings on spontaneous ovulation

In the first experiment, to clarify the role of the dorsal input to the POA-MBH passing anterior to the anterior commissure on ovulation, the anterior half-circle horizontal cut (ADC) was made anteriorly to the posterior end of the anterior commissure (Fig. 1A) on various days and ovulation was checked by the method described in the preliminary experiment.

The ADC was made in the morning (10:00-11:30 h) on 10 females (ADC-M group) or in the evening (18:00-19:30 h) on 8 females (ADC-E group) on the day of proestrus. In the ADC-I, ADC-II, ADC-III and ADC-IV groups, ADC was made in the evening of the day of diestrus II (2 days before respected estrus: 7 rats), of diestrus I (3 days before: 8 rats), of estrus (4 days before: 6 rats), of one-cycle previous proestrus (5 days before: 7 rats), respectively. Measurement of ova was started 1, 2, 3, 4 and 5 days after the operation in the ADC$\mathrm{M}$ and E, ADC-I, ADC-II, ADC-III and ADC-IV groups, respectively (see Table 1 ). In addition, to investigate the chronic effect of the ADC on ovulation, ADC was performed on the morning of proestrus in 10 females and ovulation was checked after showing 3 consecutive regular 4-day vaginal estrous cycles (cADC group).

As for brain surgery, in all ADC groups, each animal was fixed in the stereotaxic apparatus with an incisor bar set at $5 \mathrm{~mm}$ below the interaural line under ether anesthesia. An L-shaped Halász knife with a horizontal blade of $2 \mathrm{~mm}$ directed rostrally was lowered $7.0 \mathrm{~mm}$ from the bregma level with the blade tip being $1.6 \mathrm{~mm}$ anterior to the bregma on the midline and rotated $90^{\circ}$ anteriorly to both the left and right (Fig. 1A). In the sham group, the knife was lowered to the same level of the ADC and removed without rotation in 8 females. Seven females without brain surgery were prepared as a control group.

\section{Effects of lesions in the medial or bilateral lateral septum on spontaneous ovulation}

In the second experiment, medial or bilateral lateral septum was lesioned (MSL or LSL, respectively, see Fig. 1B) in 7 and 5 females, respectively, in the morning (10:00-11:30 h) of proestrus by radiofrequency lesion generator (RGF4A, Radionics Inc. Burlington, MA, USA). Number of ova was counted in the same schedule as ADC$M$ group. Rats were fixed at the stereotaxic instrument in the same condition as ADC groups 


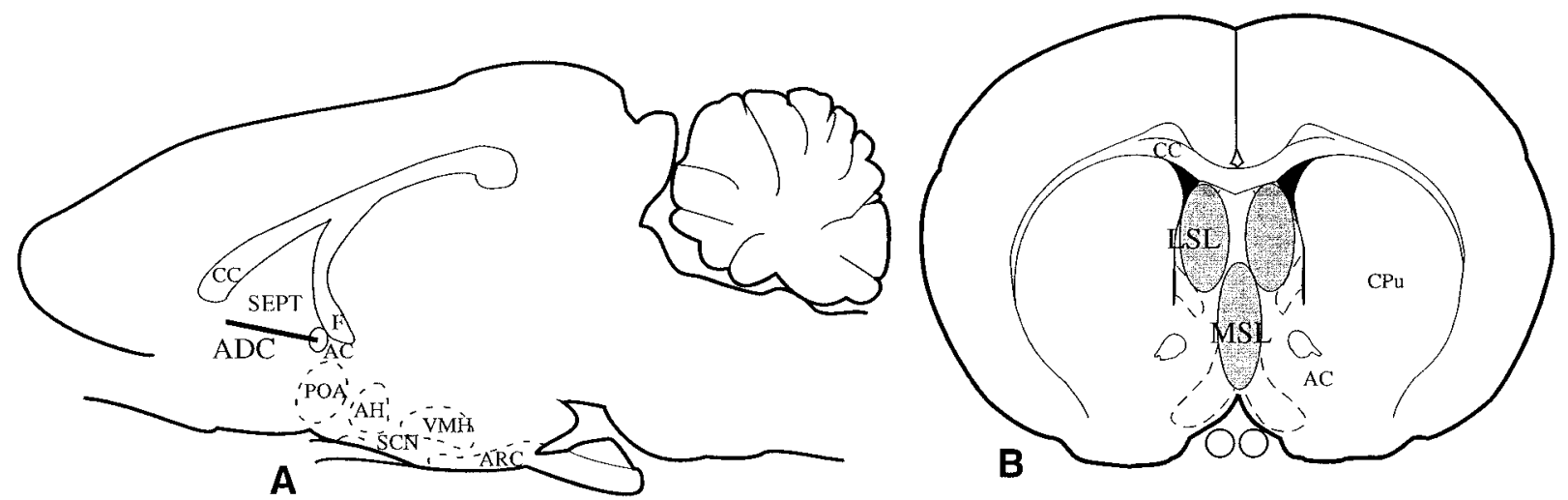

Fig. 1. A: Schematic representation of sagittal section of rat brain showing the site of anterior dorsal cut of the hypothalamus (ADC). B: Schematic representation of cross section of rat brain showing the site of medial and lateral septal lesions (MSL and LSL, respectively). AH: anterior hypothalamic nucleus; AC: anterior commissure; ARC: arcuate nucleus; CC: corpus callosum; $\mathrm{CPu}$; caudate-putamen. FX: fornix; POA: preoptic area; $\mathrm{SCN}$ : suprachiasmatic nucleus; SEPT: septum; VMH: ventromedial hypothalamic nucleus.

Table 1. Schedule of making anterior dorsal cut of the hypothalamus (ADC) or medial and lateral septal lesions (MSL or LSL) and counting ova

\begin{tabular}{|c|c|c|c|c|c|c|c|c|}
\hline Groups & Day of surgery & $\mathrm{P}$ & $\mathrm{E}$ & D I & D II & $\mathrm{P}$ & day $1(\mathrm{E})$ & days 2 (D I) \\
\hline ADC-M & proestrous morning & & & & & ADC & $\mathrm{L}$ & $\mathrm{R}$ \\
\hline ADC-E & proestrous evening & & & & & $\mathrm{ADC}$ & $\mathrm{L}$ & $\mathrm{R}$ \\
\hline ADC I & diestrous II evening & & & & ADC & & $\mathrm{L}$ & $\mathrm{R}$ \\
\hline ADC II & diestrous I evening & & & ADC & & & $\mathrm{L}$ & $\mathrm{R}$ \\
\hline ADC III & estrous evening & & $\mathrm{ADC}$ & & & & $\mathrm{L}$ & $\mathrm{R}$ \\
\hline ADC IV & proestrous evening & $\mathrm{ADC}$ & & & & & $\mathrm{L}$ & $\mathrm{R}$ \\
\hline MSL & proestrous morning & & & & & MSL & $\mathrm{L}$ & $\mathrm{R}$ \\
\hline LSL & proestrous morning & & & & & LSL & $\mathrm{L}$ & $\mathrm{R}$ \\
\hline${ }^{*} \mathrm{cADC}$ & proestrous morning & $\mathrm{ADC}$ & & -3 we & s- & & $\mathrm{L}$ & $\mathrm{R}$ \\
\hline
\end{tabular}

L or R: Counting ova in the left oviduct or right oviduct, respectively.

* cADC: Chronic anterior dorsal cut of the hypothalamus. In this group, after 3 consecutive regular 4 day estrous cycles, ovulation was checked.

under ether anesthesia. In the MSL group, an electrode $(0.7 \mathrm{~mm}$ diameter) was lowered $6.5 \mathrm{~mm}$ at a point $0.4 \mathrm{~mm}$ anterior from the bregma on the midline. Then, a current was applied and temperature at electrode tip was kept at 59-60 C for $1 \mathrm{~min}$ to make lesions. In the LSL group, the electrode was lowered $6.0 \mathrm{~mm}$ below the bregma level at a point $0.7 \mathrm{~mm}$ right and left to the midline and temperature at electrode tip was kept at 54-55 C for $1 \mathrm{~min}$.

\section{Histological examination to examine precise localization of the cuts and lesions}

All animals were killed on the second day of measurement of ova. Each brain was removed and fixed in $10 \%$ formalin solution and $100 \mu \mathrm{m}$ frozen sections were made and stained with cresyl fast violet. The cuts and lesions were evaluated according to Paxinos and Watson [18]. Some ovaries were removed and fixed in Bouin's solution and $10 \mu \mathrm{m}$ paraffin sections were made and stained with hematoxylin-eosin to observe histological condition.

\section{Statistical analysis}

The data regarding the incidence of ovulation was evaluated by means of the $\chi^{2}$-test and the comparison of the mean number of ova among groups was analyzed by unpaired student $t$-test. 


\section{Results}

\section{Measurement of number of ova on estrus and diestrus I}

In the preliminary experiment, mean numbers of ova were $7.0 \pm 0.9$ and $5.8 \pm 0.7$ in the left and right oviduct, respectively, when ovulation was checked on estrous morning. In contrast, no ova were found in both oviducts in females on diestrus I. When ovulations were checked on 2 days for each rat, the mean number of ova in the left oviduct dissected was $6.3 \pm 0.6$, on the estrus and no ova were found in the right oviduct on the diestrus I. There is no statistical difference between the mean number of ova released from the left ovary and those from the right ovary on the day of estrus. Furthermore, number of ova in the left oviduct removed by laparotomy on the day of estrus was almost the same as those in the left oviduct removed by autopsy. Thus, this method for counting ova during consecutive 2 days in unilateral oviduct is useful for investigating ovulation.

\section{Effects of transections of the dorsal inputs to the} $P O A-M B H$ at various timings on spontaneous ovulation

In the first experiment, in the control and sham groups, ova were found in all animals on the estrous day and the mean number of ova was $5.7 \pm$ 0.8 and $6.3 \pm 0.8$, respectively (Table 2 ). In contrast, no ova were found on either estrus or diestrus I in all ADC-M rats $(\mathrm{p}<0.001)$ and the ovaries had large follicles and no corpus luteum. In this group, vaginal cornification was observed in all rats on estrous morning and in 8 rats on diestrous morning. On the other hand, in ADC-E group, 6 out of 8 rats ovulated normally on estrus and the mean number of ova was comparable to those in control and sham groups.

When ADC was made on the day before proestrus (ADC I-IV groups), no ova were found either on the expected estrous day or diestrous day. One ADC III and 3 ADC IV rats ovulated on the expected diestrous day. In most ADC I-IV rats with no ovulation in the expected estrous morning, vaginal smear showed diestrous on both estrous and diestrous days. In their ovaries, small follicles and no corpus luteum were detected.

In the cADC group, all animals showed vaginal estrus the day after the surgery. In most cADC females, typical diestrous cytology of vaginal smear started to be revealed after estrus, continued $6.5 \pm$ 1.2 days, and then regular estrous cycle reappeared. The numbers of ova ovulated in all cADC rats were comparable to those in controls.

\section{Effects of lesions in the medial or lateral septum on spontaneous ovulation}

In the second experiment, neither MSL nor LSL interfered with ovulation in all rats and the average number of ova was $7.1 \pm 1.1$ and $8.6 \pm 0.6$, respectively (Table 3 ).

Table 2. Effects of anterior dorsal cut of the hypothalamus (ADC) on spontaneous ovulation in rats

\begin{tabular}{|c|c|c|c|c|c|c|c|c|}
\hline \multirow[t]{2}{*}{ Groups } & \multirow{2}{*}{$\begin{array}{l}\text { No. } \\
\text { of rats }\end{array}$} & \multicolumn{3}{|c|}{ Day 1 (expected estrus) } & \multicolumn{3}{|c|}{ Day 2 (expected diestrus I) } & \multirow[b]{2}{*}{$\begin{array}{l}\text { Body weight } \\
\text { (g) }\end{array}$} \\
\hline & & $\begin{array}{c}\text { No. of rats } \\
\text { ovulated (\%) }\end{array}$ & $\begin{array}{c}\text { No. of ova } \\
\text { (Mean } \pm \text { S.E.) }\end{array}$ & $\begin{array}{c}\text { Incidence of } \\
\text { vaginal estrus }\end{array}$ & $\begin{array}{c}\text { No. of rats } \\
\text { ovulated (\%) }\end{array}$ & $\begin{array}{c}\text { No. of ova } \\
\text { (Mean } \pm \text { S.E.) }\end{array}$ & $\begin{array}{c}\text { Incidence of } \\
\text { vaginal estrus }\end{array}$ & \\
\hline Control & 7 & $7 / 7 \quad(100)$ & $5.7 \pm 0.8$ & $7 / 7$ & $0 / 7 \quad(\quad 0)$ & - & $0 / 7$ & $274 \pm 5$ \\
\hline Sham & 8 & $8 / 8 \quad(100)$ & $6.3 \pm 0.8$ & $8 / 8$ & $0 / 8 \quad(\quad 0)$ & - & $0 / 8$ & $268 \pm 14$ \\
\hline ADC-M & 10 & $0 / 10^{*}(0)$ & - & $10 / 10$ & $1 / 10(10)$ & 9 & $8 / 10$ & $261 \pm 5$ \\
\hline ADC-E & 8 & $6 / 8^{* *}(75)$ & $6.2 \pm 1.0$ & $8 / 8$ & $0 / 8 \quad(\quad 0)$ & - & $0 / 8$ & $255 \pm 6$ \\
\hline ADC I & 7 & $0 / 7^{*}\left(\begin{array}{l}0 \\
0\end{array}\right.$ & - & $4 / 7$ & $0 / 7 \quad(\quad 0)$ & - & $0 / 7$ & $277 \pm 11$ \\
\hline ADC II & 8 & $0 / 8^{*}(0)$ & - & $0 / 8$ & $0 / 8 \quad(\quad 0)$ & - & $0 / 8$ & $270 \pm 11$ \\
\hline ADC III & 6 & $0 / 6^{*}(0)$ & - & $0 / 6$ & $1 / 6 \quad(16.7)$ & 6 & $1 / 6$ & $253 \pm 10$ \\
\hline ADC IV & 7 & $0 / 7^{*}(0)$ & - & $0 / 7$ & $3 / 7 \quad(42.9)$ & $6.7 \pm 1.8$ & $3 / 7$ & $293 \pm 16$ \\
\hline cADC & 10 & $10 / 10(100)$ & $6.1 \pm 0.8$ & $10 / 10$ & $0 / 10\left(\begin{array}{l}0 \\
0\end{array}\right)$ & - & $0 / 10$ & $304 \pm 10$ \\
\hline
\end{tabular}

No. of ova: mean number of ova in ovulated rats.

${ }^{*} \mathrm{p}<0.001$ vs Control and Sham, ${ }^{* *} \mathrm{p}<0.001$ vs ADC-M. 
Table 3. Effects of medial or lateral septal lesions (MSL or LSL) on spontaneous ovulation in female rats

\begin{tabular}{|c|c|c|c|c|}
\hline \multirow[t]{2}{*}{ Gropus } & \multirow{2}{*}{$\begin{array}{l}\text { No. } \\
\text { of rats }\end{array}$} & \multicolumn{3}{|c|}{ Day 1 (expected Estrus) } \\
\hline & & $\begin{array}{c}\text { No. of rats } \\
\text { ovulated (\%) }\end{array}$ & $\begin{array}{c}\text { No. of ova } \\
\text { (Mean } \pm \text { S.E.) }\end{array}$ & $\begin{array}{c}\text { Incidence of } \\
\text { vaginal estrus }\end{array}$ \\
\hline MSL & 7 & (100) & $7.1 \pm 1.1$ & $7 / 7$ \\
\hline LSL & 5 & (100) & $8.6 \pm 0.6$ & $5 / 5$ \\
\hline
\end{tabular}

No. of ova: mean number of ova in ovulated rats.

\section{Precise location of the cuts and lesions in the brain}

In the histological examination, the cuts in all groups with ADC were located above the anterior commissure and extended from the end of the anterior commissure to the anterior part of the medial septal nucleus. In some ADC females, small lesions from the lowering of the knife were found in the midline of the septum. However, there was no detectable difference in the incidence of ovulation among animals with different grades of lesions.

The MSL was found from the level of the rostral level of the medial septal nucleus to the level of the rostral part of the fornix. Most parts of the medial septal nucleus were destroyed in MSL group. In some females, MSL invaded into the lateral septal area. The LSL was located from the level of posterior part of the genu corpus callosum to the level of the rostral part of the fornix. Most parts of the lateral septum were damaged, but caudal and rostral tips of the lateral septum were intact. In some LSL rats, lesions extended to a part of the striatum.

\section{Discussion}

In the first experiment, the ADC which was performed in the morning of proestrus, but not in the evening, suppressed spontaneous ovulation. This result agrees with the reports that the dorsal afferents of the POA-MBH passing anterior to the anterior commissure play an important role in triggering ovulation [15-17]. Furthermore, even when ADC was performed in the evening of onecycle previous proestrous day, ovulation was also blocked on the estrous day of the measurement. These indicate possibility that at a minimum, 2 successive ovulations can be suppressed by the
ADC in 4-day estrous cycle rats. Seven days after making the ADC, the regular estrous cycle reappeared in the cADC group. In some ADC III and ADC IV rats, delayed ovulation was seen. From these facts, the role of the fibers interrupted by the ADC might be recovered by regeneration or be compensated for by other mechanisms. Such recovering from inhibition of ovulation has been reported in female rats with transection of the stria terminalis [19].

Destruction of the medial amygdala on the day of proestrus inhibits ovulation [10], conversely electrical stimulation advances the time of the LH surge $[8,9]$. The bed nuclues of stria terminalis (BST) is also involved in the ovulation regulating system [19]. The amygdala and the BST have been reported to be connected anatomically with the POA and the MBH [20-22] by neural fibers passing through the dorsal part of the hypothalamus. The multiple unit activity of the medial amygdala as well as of the POA and arcuate nucleus begins to increase on the day of diestrus II or on the morning of proestrus and continues until the afternoon of the estrus [23]. These lead to the possible conclusion that the inhibitory effect on ovulation of the ADC is due to the interruption of the signals from the amygdala and the BST.

The ADC may also transect some fibers from the hippocampus. However, because the hippocampus is thought to inhibit ovulation [24], the hippocampal influence can be excluded from the cause of inhibition of ovulation by the ADC. The serotonergic neurons in the dorsal raphe nucleus [12-14] and the noradrenergic neural fibers from the lower brainstem are important in modifying the ovulatory mechanisms [13, 25]. These influences are thought not to be disturbed by the $\mathrm{ADC}$ in an anatomical view, because these neurons mainly pass through the medial forebrain bundle and affect the functions of the hypothalamus [26- 
28].

The septal area sends fibers to the POA and lower brain stem passing through the medial forebrain bundle [29]. This septal fiber is cut by the ADC. The medial septum contains GnRH neurons in the rat brain and projects fibers mainly to the median eminence $[30,31]$. In contrast, the number of $\mathrm{GnRH}$ neurons in the lateral septum is small and the nucleus sends the GnRH fibers to the POA but not to the median eminence [21]. In this experiment, destruction of the medial or lateral septum performed on the morning of proestrous had no effect on ovulation. Similar results have been reported in females with medial septal lesions [32]. Moreover, the horizontal cut in the ventral of the septum has been reported to reduce contents of GnRH in the median eminence but have no influence on ovulation [31]. Although GnRH neurons in the septal area are partially contributed to ovulatory mechanisms, the inhibitory effect on the ovulation by the ADC is not due to the interruption of fibers from the septum including the GnRH neurons. Furthermore, fibers passing through the areas by the MSL or LSL to the lower central nervous system are not involved in the ovulatory function.

Further experiments are necessary to identify the origin and terminal portion of the dorsal fibers of the POA and $\mathrm{MBH}$.

\section{Acknowledgements}

This study was supported by a Grant-in-Aid to K.Y. from the Ministry of Education, Science, Sports and Culture of Japan (11640669) and Waseda University Grant for Special Research Projects (99A580).

\section{References}

1. Taleisnik S, McCann SM. Effects of hypothalamic lesions on the secretion and storage of hypophysial luteinizing hormone. Endocrinology 1961; 68: 263272.

2. Clemens JW, Smalostig EB, Sawer RD. Studies on the role of the preoptic area in the control of reproductive function in the rat. Endocrinology 1976; 99: 728-735.

3. Wiegand SJ, Terasawa E, Bridson WE, Goy RW. Effects of discrete lesions of preoptic and suprachiasmatic structures in the female rat, Alterations in the feedback regulation of gonadotropin secretion. Neuroendocrinology 1980; 31: 147-157.

4. Freeman ME. The neuroendocrine control of the ovarian cycle of the rat. In: Knobil E, Neill JD (eds.), The Physiology of Reproduction, New York: Raven 1994; 613-658.

5. Sarkar DK, Chiappa SA, Fink G. Gonadotropinreleasing hormone surge in pro-oestrous rats. Nature 1976; 264: 461-463.

6. Witkin JW, Paden CM, Silverman AJ. The luteinizing hormone-releasing hormone (LHRH) systems in the rat brain. Neuroendocrinology 1982; 35: 429-438.

7. Merchenthaler I, Göres T, Sétáló G, Petrusz P, Flerkó B. Gonadotropin-releasing hormone $(\mathrm{GnRH})$ neurons and pathways in the rat brain. Cell Tissue Res. 1984; 237: 15-29.

8. Kawakami M, Kimura F. Inhibition of ovulation in the rat by electrical stimulation of the lateral amygdala. Endocrinol Japon 1975; 22: 61-65.

9. Carrillo AJ, Rabii J, Carrer HF, Sawyer CH. Modulation of the proestrous surge of luteinizing hormone by electrochemical stimulation of the amygdala and hippocampus in the unanesthetized rat. Brain Res 1977; 128: 81-92.

10. Sanchez MA, Dominguez R. Differential effects of unilateral lesions in the medial amygdala on spontaneous and induced ovulation. Brain Res Bull 1995; 38: 313-317.

11. Kawakami M, Kimura F. Cholinergic and serotonergic neural links and the inhibitory effects of hippocampus, lateral amygdala and central gray matter on gonadotropin release. Endocrinol Japon 1976; 23: 11-21.

12. Morello H, Taleisnik S. Changes of the release of luteinizing hormone $(\mathrm{LH})$ on the day of proestrus after lesions or stimulation of the raphe nuclei in rats. Brain Res 1985; 360: 311-317.

13. Morello H, Taleisnik S. The inhibition of proestrous LH surge and ovulation in rats bearing lesions of the dorsal raphe nucleus is mediated by the locus coeruleus. Brain Res 1988; 440: 227-231.

14. Maekawa F, Tsukahara S, Tsukamura H, Maeda K-I, Yamanouchi K. Prevention of inhibitory effect of dorsal raphe nucleus lesions on ovulation and LH surge by 5 -HT $2 \mathrm{~A} / 2 \mathrm{C}$ receptor agonists in female rats. Neurosci Res 1999; 35: 291-298.

15. Taleisnik S, Velasco ME, Astrada JJ. Effect of 
hypothalamic deafferentation on the control of luteinizing hormone secretion. J Endocrinol 1970; 46: $1-7$.

16. Van Rees GP. Control of ovulation by the anterior pituitary gland. Progress in Brain Res 1972; 38: 193210.

17. Kimura F, Kawakami M. Reanalysis of the preoptic afferents and efferents involved in the surge of LH, $\mathrm{FSH}$ and prolactin release in the proestrous rat. Neuroendocrinology 1978; 27: 74-85.

18. Paxinos G, Watson C. The Rat Brain in Stereotaxic Coordinates. 2nd ed, New York: Academic Press; 1986.

19. Velasco ME, Taleisnik S. Effects of the interruption of amygdaloid and hippocampal afferents to the medial hypothalamus on gonadotrophin release. J Endocrinol 1971; 51: 41-55.

20. Maclean PD. Fiber systems of the forebrain. In: Paxinos G (ed.), The Rat Nervous System. Vol.1, Academic Press, 1985: 417-483.

21. Simerly RB, Swanson LW. The organization of neural inputs to the medial preoptic nucleus of the rat. J Comp Neurol 1986; 246: 312-342.

22. Canteras NS, Simerly RB, Swanson LW. Organization of projections from the medial nucleus of the amygdala: A PHAL study in the rat. J Comp Neurol 1995; 360: 213-245.

23. Kawakami M, Kimura F. Possible roles of CNS estrogen-neuron systems in the control of gonadotropin release, In: Stumpf WE, Grant LD (eds.), Anatomical Neuroendocrinology. S. Karger, 1975: 216-231.

24. Velasco ME, Taleisnik S. Effect of hippocampal stimulation on the release of gonadotropin. Endocrinol 1969; 85: 1154-1159.

25. Kawakami M, Ando S. Lateral hypothalamic mediation of midbrain catecholaminergic influences on preovulatory surges of serum gonadotropin and prolactin in female rats. Endocrinol 1981; 106: 66-71.

26. Parent A, Descarries L, Beaudet A. Organization of ascending serotonin systems in the adult rat brain. A radioautographic study after intraventricular administration of $[3 \mathrm{H}] 5$ hydroxytryptamine. Neurosci 1981; 6: 115-138.

27. Pickel VM, Segal M, Bloom FE. A radioautographic study of the efferent pathways of the nucleus locus coeruleus. J Comp Neurol 1974; 15: $15-42$.

28. Aston-Jones G, Shipley MT, Grzanna R. The locus coeruleus, A5 and A7 noradrenergic cell groups. In Paxinos G (ed.), The Rat Nervous System. 2nd ed, Academic Press: San Diego, 1995: 183-213.

29. Veening JG, Swanson LW, Cowan WM, Nieuwenhuys R, Geeredts LMG. The medial forebrain bundle of the rat II. An autoradiographic study of the topography of the major descending and ascending components. J Comp Neurol 1982; 206: 82-108.

30. Silverman AJ, Jhamandas J, Renaud LP. Localization of luteinizing hormone-releasing hormone (LHRH) neurons that project to the median eminence. J Neurosci 1987; 7: 2312-2319.

31. Köves K, Molnar J. Effects of various hypothalamic deafferentation injuring different parts of the GnRH pathway on ovulation, GnRH content of the median eminence, and plasma LH and FSH levels. Neuroendocrinology 1986; 44: 172-183.

32. Kawakami M, Ando S. Forebrain structures involved in ovulation and release of serum LH and FSH in proestrous rats. Brain Res 1980; 191: 99-108. 